\section{On the rocks}

\author{
K.G. Cox
}

Magmas and Magmatic Rocks: An Introduction to Igneous Petrology. By Eric A.K. Middlemost. Longman:1985. Pp.266. Pbk 114.95 .

Igneous Petrology. By Alexander R. McBirney. Freeman, Cooper/Oxford University Press:1985. Pp.504. \$38.75, £37.50.

The Field Description of Igneous Rocks. By Richard Thorpe and Geoff Brown. Open University Press/Halsted Press: 1985. Pp.154. Pbk £6.95; hbk \$13.95.

STUDENTS of igneous petrology are particularly well served by textbooks at present. Whether the explosion in publications at this level has been a consequence of the generally healthy state of the earth sciences, and specifically of igneous petrology, as a result of the rise of the X-ray fluorescence spectrometer and the electron microprobe, or whether it is due to erosion of academic salaries, is not clear. The fact remains that there are now at least half-a-dozen reasonably up-to-date and general texts to choose from.

Magmas and Magmatic Rocks by Eric Middlemost will find a place among the best of them. To give an idea of its particular flavour it is worth back-tracking to that classic of petrological writing Igneous and Metamorphic Petrology by Turner and Verhoogen, published in 1951 with a second edition in 1960. Turner and Verhoogen was strong on taxonomy, on grouping the diverse world of natural rocks into a small number of associations, and in digesting and presenting petrogenetic ideas. For those of us used to this view of the world, Middlemost is a familiar but very welcome newcomer. It is a rather short book, essentially in the Turner and Verhoogen style, but contains the information one would want to find. It is strong on descriptive details (particularly the geochemical) and presents sensible consensus petrogenetic ideas. It is less authoritative on magmatic processes, but so was Turner and Verhoogen, and it deserves to become a widely used and successful textbook.

Alexander McBirney's Igneous Petrol$o g y$ is an equally impressive but very different work. McBirney has always been in the forefront of the new wave of igneous geologists who are rather more concerned with how magmas behave than with what rocks are, an approach originating more in volcanology than in geochemistry and petrology. Times change, and the ideal student of the future will absorb what both Middlemost and McBirney have to say. However, McBirney is currently likely to be less popular. The book is long and rather expensive, with a high intellectual content that places considerable demands upon the reader. Much of it is permeated by the concepts of thermodynamics and fluid dynamics, with many quantitative examples, culminating in an appendix of intriguing problems (answers are not given).

The committed student will find this book a gem, and it points the way that igneous petrology will undoubtedly take in the future. It is perhaps a pity, however, that the author has attempted to make the book comprehensive by including large amounts of descriptive information in a manner rather similar to Middlemost. These sections are written with less conviction than the others, and I would have preferred to see a shorter book with more concentration on McBirney's special talents.

\section{Settling standards}

\section{Philip Allen}

Principles of Physical Sedimentology. By J.R.L. Allen. Allen \& Unwin:1985. Pp.272. Hbk£30, \$40; pbk£14.95, \$24.95. Experiments in Physical Sedimentology. By J.R.L. Allen. Allen \& Unwin:1985. Pp.63. Pbk£7.95, \$9.95.

JoHn Allen's textbook, Physical Processes of Sedimentation (Allen \& Unwin, 1970), was an early attempt to explain sedimentary mechanisms in terms of physical principles. In its insistence on a rigorous physical approach it echoed the tones of Bagnold's classic The Physics of Blown Sand and Desert Dunes (Chapman \& Hall, 1954), and very much set the standard for students to follow. However, now over 15 years old, it was in need of revision and the present volume admirably succeeds in this task. The new book is accompanied by a helpful practical manual which describes 28 experiments illustrating some of the main principles of physical sedimentology.

In reality, little has occurred in the past 15 years with truly fundamental implications for the fields of loose boundary hydraulics and bedforms, with the notable exception of the development of ideas, germinated in the 1960 s, on the nature of turbulence. The main differences between Principles of Physical Sedimentology and its predecessor is the inclusion of a new chapter on results of flow-visualization studies of turbulence and, the new vogue, the processes and mechanisms affecting muds.

Many students in sedimentology are daunted by equations describing processes which they do not have the basic knowledge to understand qualitatively, let alone quantitatively. The first chapter sets out to provide some of the basic rules of
The Field Description of Igneous Rocks is the latest addition to the Geological Society of London's Handbook series. It is a small, soft-covered yet tough, volume which all undergraduates embarking on their finals mapping project should carry in their knapsacks. Apart from containing the obvious things such as hints on how to keep a field notebook and on other specific field skills, it includes a great deal of general information on the topics of volcanology and the structures of plutonic rocks. It is thus a highly useful introductory text for those studying any aspect of igneous geology, and should have many applications in class work as well as in the field.

K.G. Cox is a Lecturer in the Department of Earth Sciences, University of Oxford, Parks Road, Oxford OX1 3PR, UK.

fluid mechanics that can be used in the following 12 chapters, but it could easily have been twice as long, for it is these basics which provide the essential insights to sedimentology problems. For this reason I would have preferred a section at this stage on the structure of turbulent boundary layers rather than discovering it relegated to Chapter 6 . Two further chapters, one considering the description of detrital particles and their packing, the other dealing with the settling of particles in a stagnant fluid (in effect an analysis of drag), complete this section on fundamentals.

Entrainment, sediment transport and the resultant bedforms in a cohesionless substrate should form the core of any book on physical sedimentology. Allen discusses this topic for unidirectional flows surprisingly briefly; equivalent information about oscillatory flows is found in the very last chapter and one has to wait tantalizingly for two chapters before a statement on suspended sediment transport is encountered. Even so, these individual chapters provide a marvellous physical background for the student.

Looming large in the second half of the book is a discussion of mass movements in general, with a concentration on gravity currents in the sea (turbidity currents). Additional chapters deal with the properties, deposition and erosion of muddy sediments and there is an interesting discourse on deformation of unconsolidated sediments.

Despite the curiosities in its organization and the idiosyncratic chapter headings, Principles of Physical Sedimentology will be an important text for students interested in the explanatory nature of sedimentology. It represents another fine contribution from a remarkable sedimentologist.

Philip Allen is a Lecturer in the Department of Earth Sciences, University of Oxford, Parks Road, Oxford OXI 3PR, UK. 